Research Paper

\title{
Effect of design and operating parameters on the thermal performance of aluminum flat grooved heat pipes
}

\author{
Hossein Alijani ${ }^{a}$, Barbaros Çetin ${ }^{a, *}$, Yiğit Akkuş ${ }^{b}$, Zafer Dursunkaya $^{c}$ \\ a Microfluidics and Lab-on-a-chip Research Group, Mechanical Engineering Department, I.D. Bilkent University, 06800 Ankara, Turkey \\ ${ }^{\mathrm{b}}$ ASELSAN A.S.., 06172 Yenimahalle, Ankara, Turkey

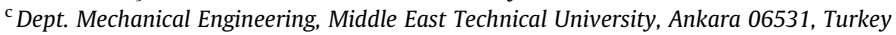

\section{H I G H L I G H T S}

- Three performance indicators used including a newly defined heat pipe effectiveness.

- Optimum operation is discussed based on existence/absence of dryout in the grooves.

- Near optimum, dryout tendency increases with increasing groove density and heat flux.

- Effectiveness increases with groove density, and drops with increasing heat flux.

\section{A R T I C L E I N F O}

\section{Article history:}

Received 6 August 2017

Revised 28 November 2017

Accepted 23 December 2017

Available online 27 December 2017

\section{Keywords:}

Flat plate heat pipe

Grooved wick

Thermal performance

Filling ratio

Dryout

\begin{abstract}
A B S T R A C T
Four aluminum flat grooved heat pipes with groove widths of $0.2,0.4,0.8$ and $1.6 \mathrm{~mm}$ are fabricated and the effect of filling ratio on the thermal performance is experimentally studied for four different heat flux values of $2.1,3.2,4.2$ and $5.3 \mathrm{~W} / \mathrm{cm}^{2}$. An optimum filling ratio corresponding to each heat flux is determined where the heat pipe has the best thermal performance. Thermal performance of the heat pipes are evaluated using three indicators; (i) the temperature difference between the heat source and heat sink surfaces, (ii) the temperature difference between the peak system temperature and the temperature of the cooling ambient and (iii) heat pipe effectiveness defined as a temperature difference ratio under dry and operating conditions. A flow and evaporative mass scaling model is developed to interpret the experimental findings. Experimental results reveal that at the optimum point the heat pipe with the $0.4 \mathrm{~mm}$ groove width has the best thermal performance, and the heat pipe with the smallest $0.2 \mathrm{~mm}$ groove operates under dryout conditions even for the lowest heat flux, the reason of which is discussed based on interpretation of underlying phase change physics. Experiments reveal the existence of two operating regimes; with and without dryout in the grooves. Although higher heat loads can be carried under dryout conditions, a limit exists for the maximum heat flux where the pipe operates without the onset of dryout for a specific groove density.
\end{abstract}

(C) 2017 Elsevier Ltd. All rights reserved.

\section{Introduction}

The growing demand for boosting functionality of electronic devices requires higher number of transistors to be placed on one single chip. Developments in microfabrication and MEMS technology enable the manufacturing of single chips having more than one billion transistors on a small area of silicon [1]. While the performance of such electronic components has been dramatically improving and their size has been diminishing over time, their

\footnotetext{
* Corresponding author.

E-mail addresses: barbaros.cetin@bilkent.edu.tr, barbaroscetin@gmail.com (B. Çetin).
}

thermal management becomes more challenging and requires the development of novel methods to prevent the malfunction or irreversible damage of electronic components. Heat pipes are commonly applied in the thermal management of electronic components. They use the phase change heat transfer mechanism, which enables the transfer of large amounts of heat from a source to a sink with small temperature gradients [2]. Moreover, heat pipes require no external pumping power, which makes them reliable and vibration-free. In addition to the thermal management of electronics/electrical devices, they are widely used in many terrestrial and aerospace applications [3,4].

Heat pipes can be fabricated in many types including two-phase closed thermosyphons, capillary-driven heat pipes, annular heat 


\author{
Nomenclature \\ DI deionized \\ $F \quad$ fin width, $\mathrm{mm}$ \\ $H \quad$ groove depth, mm \\ IPA isopropyl alcohol \\ $\Delta T \quad$ temperature different between the two most distant \\ thermocouples, $T_{1}-T_{5},{ }^{\circ} \mathrm{C}$ \\ TC thermocouple \\ $V_{\text {fluid }} \quad$ total volume of the working fluid inside a heat pipe \\ $V_{\text {groove }}$ total volume of all the grooves of a heat pipe \\ W groove width, $\mathrm{mm}$ \\ Greek symbols \\ $\alpha \quad$ contact angle
}

$\begin{array}{ll}\varepsilon_{h p} & \text { heat pipe effectiveness } \\ \theta & \text { edge angle } \\ \begin{array}{ll}\text { Subscript } \\ \text { dry } & \text { dry operating condition corresponding to filling ratio of } \\ \text { eff } & \text { zero } \\ h p & \text { effective } \\ \text { operating operating condition at a filling ratio higher than zero } \\ \text { water cooling water reservoir }\end{array}\end{array}$

pipes, micro and miniature heat pipes, vapor chambers, capillarypumped loop heat pipes, pulsating heat pipes, rotating heat pipes, gas-loaded heat pipes, loop heat pipes and inverted meniscus heat pipes [5]. In particular, capillary-driven heat pipes utilize a wick structure to provide sufficient capillary pressure to pump the liquid working fluid to the evaporator section. Porous structure, screen mesh, non-circular micro-channels with sharp-angled corners and axial grooves are some examples of wick structures, which enable the heat pipes to function even against or in the absence of gravity [5]. For the case of grooved wick structures, various groove geometries have been studied in the literature such as fan-shaped [6], circular [7], reentrant [8,9] triangular [9,10], trapezoidal [7-9,11-13] and rectangular [7-9,12,14-27] cross-sections. Particularly, heat pipes with rectangular grooves can be easily modeled and/or numerically studied due to the simplicity of the groove geometry $[28,29]$. Thermal performance of a heat pipe can be influenced by a variety of factors such as wall material, wick structure [30-32], working fluid [18] and its charge amount [6,22,23,33], input heat load, and inclination angle [24,34].

Flat plate, or simply, flat heat pipes have been investigated in many studies due to the ease of manufacturing and experimentation. Due to its superior thermal conductivity and compatibility with various working fluids, copper has been typically selected as the base material for heat pipes, and has been at the focus of many studies in the literature [12,22-24]. In a pioneering study, Hopkins et al. [12] compared the maximum heat transfer capability of flat heat pipes with rectangular and trapezoidal groove geometries. They concluded that among the investigated heat pipes, narrower or deeper grooved wick structures had a better heat removal performance. The effect of boiling, which is considered as a limitation on the performance of a heat pipe, was investigated at different filling ratios [22]. For heat pipes charged with $n$-pentane, effects of filling ratio and vapor space thickness have been theoretically analyzed and experimentally investigated [23]. Based on the results, optimal filling ratio for the vapor space thickness of $2 \mathrm{~mm}$ is in the range of $1.0-2.5$, corresponding to a minimum value in total thermal resistance of the heat pipe. Moreover, a very small or very high vapor space thickness results in trapping of the working fluid in the corners and sides of the heat pipe or dominating the gravitational forces and flooding the grooves, both adversely affecting the performance of the heat pipe. Thermal performance of a copper flat grooved heat pipe with axial rectangular grooves charged with different concentrations of a designer fluid was experimentally studied for different inclination angles [24]. Compared to water, a chemically advanced working fluid demonstrated a better performance by lowering the thermal resistance of the heat pipe by approximately $20 \%$ and extending the onset of dryout to higher heat loads. Furthermore, the proposed working fluid could make the heat pipe operate at higher inclination angles due to the creation of surface structures.

Although copper is a common base material for heat pipes, despite its lower thermal conductivity, aluminum is a suitable candidate for heat pipes in aerospace applications, e.g. unmanned spacecrafts, and low temperature operating conditions due to its lightweight, high electrical and thermal conductivity and ease of machining [35]. Recently, many studies have been carried out to assess the thermal performance of aluminum heat pipes $[20,21,25,26,33,36,37]$. The effects of filling ratio [27,33] and the groove density [33] on the thermal performance of aluminum heat pipes were investigated for acetone and IPA, and an optimum filling ratio was indicated for each heat pipe studied. In a further study, the effect of filling ratio on the heat pipes with different lengths and bending angles were also investigated for an aluminum heat pipe with acetone [38]. The effect of the surface modification of the inner groove surfaces was studied, and an improvement in thermal performance of an aluminum grooved heat pipe was observed as a result of increase in the capillary pressure [20]. The possible heat transfer enhancement through the use of acetone-based nanofluids in the heat pipes was investigated for $\mathrm{Al}_{2} \mathrm{O}_{3}$ nanoparticles [21] and multi-wall carbon nanotubes [26], and it was shown that replacement of the working fluid with a nanofluid resulted in a better performance. The performance of aluminum heat pipes with inorganic aqueous solutions was compared to that of copper heat pipes with water, and it was concluded that aluminum ones have a potential for replacing conventional copper/water ones [25]. The details of the studies regarding flat heat pipes (both copper and aluminum) with rectangular grooves are summarized in Table 1 . Thermal performance of heat pipes have been assessed using different performance indicators in the literature. These indicators are also included in the summary table.

Miniaturization of high heat dissipating electronic devices pushes thermal design engineers to seek solutions to remove more heat within a limited available space. Today, as a commonly applied thermal solution in electronics cooling, heat pipes are desired to carry higher heat loads without an increase in size. Therefore, the optimization of the available wick structures is of importance. After the experimental study of Hopkins et al. [12], which promoted the use of narrower and deeper grooves, there has been numerous analytical and numerical studies concentrating on the optimization of rectangular grooves [39-41]. Increasing the groove aspect ratio (depth/width) was reported to significantly enhance the maximum sustainable heat flux that heat pipe can carry before reaching the dryout limit [39]. However, there are two main issues which restrict the performance of wicks in high aspect ratio grooves. The first one is the cross-sectional area in the vapor region, which reduces with increasing groove height 
Table 1

Studies on flat grooved heat pipes in the literature.

\begin{tabular}{|c|c|c|c|c|c|}
\hline Reference & $\begin{array}{l}\text { Wall } \\
\text { Material }\end{array}$ & $\begin{array}{l}\text { Grooves dimensions } \\
\mathrm{W} \times \mathrm{H}[\mathrm{mm} \times \mathrm{mm}]\end{array}$ & Working fluid(s) & Different filling ratios & Performance indicator \\
\hline Hopkins et al. [12] & Copper & $0.2 \times 0.42$ & Water & - & $\begin{array}{l}\text { Heat pipe thermal resistance, } \\
\text { maximum heat transfer rate }\end{array}$ \\
\hline Lips et al. [23] & Copper & $0.4 \times 0.4$ & $n$-pentane & $0-80 \%^{\mathrm{b}}$ & Thermal resistance \\
\hline Supowit et al. [24] & Copper & $1.5 \times 2$ & $\begin{array}{l}\text { DI water, } \\
\text { inorganic aqueous solutions }\end{array}$ & - & Thermal resistance \\
\hline Lips et al. [22] & Copper & $0.4 \times 0.4$ & Methanol & $1.3,1.6$, and $2.8^{a}$ & Thermal resistance \\
\hline Dean et al. [18] & Silicon & $0.1 \times 0.1$ & Liquid $\mathrm{Hg}$ & - & $\begin{array}{l}\text { Temperature drop along the top lid, } \\
\text { effective thermal conductivity }\end{array}$ \\
\hline Stubblebine and Catton [25] & Aluminum & $1.5 \times 2$ & $\begin{array}{l}\text { Water, } \\
\text { inorganic aqueous solutions }\end{array}$ & - & $\begin{array}{l}\text { Thermal resistance, } \\
\Delta T \text { between the heat source and sink }\end{array}$ \\
\hline Hao et al. [26] & Aluminum & $0.3 \times 0.65$ & $\begin{array}{l}\text { Acetone, } \\
\text { Acetone-based nanofluids }\end{array}$ & $20,30,40 \%^{b}$ & $\begin{array}{l}\text { Thermal resistance, } \\
\text { Effective thermal conductivity }\end{array}$ \\
\hline Chen and Chou $[27,38]$ & Aluminum & $0.2 \times 0.4$ & Acetone & $5-50 \%^{b}$ & $\begin{array}{l}\text { Thermal resistance, } \\
\text { effective thermal conductivity, } \\
\Delta T \text { between the heat source and sink, } \\
\text { maximum heat transport capability }\end{array}$ \\
\hline Kim et al. [37] & Aluminum & Not reported & Acetone & - & Thermal resistance \\
\hline Alijani et al. [33] & Aluminum & $\begin{array}{l}0.2 \times 0.2 \\
0.4 \times 0.4 \\
1.5 \times 2.0\end{array}$ & Isopropyl alcohol & $0-25.0^{\mathrm{a}}$ & $\Delta T$ between the heat source and sink \\
\hline
\end{tabular}

\footnotetext{
a Compared to total volume of the grooves.

b Compared to internal volume of the heat pipe.
}

when the total height of the heat pipe is kept constant. This reduction leads to higher flow resistance in the vapor region. The second limitation is due to the increase of the conduction path between the groove base and the fin top corner of the groove, where majority of evaporation takes place. Increased conduction path adds an additional thermal resistance, which is undesired especially in the cooling of electronic components. Although the aforementioned effects seem to suggest the presence of an optimum aspect ratio for rectangular grooves, machining of high aspect ratio grooves, especially for smaller groove widths, can be challenging due to manufacturing constraints and/or may not feasible considering the manufacturing cost.

\subsection{Scope of the present study}

The current study investigates the performance of grooves with an aspect ratio of 1.0 which can be fabricated by cost effective micro-machining process. The combined effects of groove density and the amount of the working fluid, from fully-flooded to dry, were reported for aluminum flat grooved heat pipes in [33]. The present work extends the previous experimental study by including the effect of different heat loads $\left(2.1,3.2,4.2\right.$ and $\left.5.3 \mathrm{~W} / \mathrm{cm}^{2}\right)$ on the thermal performance for a broader set of groove widths $(0.2,0.4,0.8$ and $1.6 \mathrm{~mm})$, which approximately covers the entire practical width spectrum having an adequate capillary pumping effect with feasible manufacturing. Three indicators are used in the assessment of the thermal performance of the heat pipes. Two of these are related to the extremum temperatures in the system one being the temperature difference between the heat source and heat sink surfaces, and the second being the temperature difference between the peak system temperature and the temperature of the cooling ambient. A new dimensionless thermal performance indicator, heat pipe effectiveness, is introduced and used in the assessment of thermal performance replacing the commonly used thermal performance parameters such as effective thermal conductivity and thermal resistance. Furthermore, a flow and evaporative mass scaling model is introduced to explain the two distinct regimes of operation encountered in the case of different heat loads and heat pipe grooves. The findings establish a basis for optimization of heat pipe groove density and filling ratio for different application specifications of heat load and maximum temperature.

\section{Flow and evaporative mass scaling}

In this section, a scaling of groove and evaporative mass flow is presented, and will be used in the interpretation of results. Fig. 1 shows the geometry of a single groove of the heat pipe. The length of the heat pipe is $L, w$ is the groove width and $h$ is the groove height. The angle at the vapor-liquid-solid interface is denoted by the "edge angle", which at the limit will reach the contact angle, $\alpha$. Heat is added and removed at the bottom surface in the heater and cooler, respectively, separated by an adiabatic section. The vapor is at the vapor temperature, $T_{v}$, and the fin top temperature varies along the axis from a value less than that of the vapor in the condenser to a value larger than vapor in the evaporator. The location where the fin top temperature is equal to the vapor temperature separates the condenser from the evaporator, the exact position of which is a function of operating conditions. The length of the evaporator section is $\ell_{\text {evap }}$, which may detach from the end of the groove in dryout operation. A portion of the condenser may contain liquid above the groove-depending on the amount of fluid charge-and this region is the flooded domain. The capillary pressure difference occurs due to the existence of a radius of curvature on the surface, therefore it is assumed that the magnitude of flow is small in the flooded region and the effective flow length, $\ell_{\text {eff }}$ defines the region where flow inside the channel exists. The presence of dryout in the evaporator section also shortens the extent of the flow region.

The mass flow rate in the channel is given by

$\dot{m}_{\text {flow }}=\rho A \bar{U} \sim w h \bar{U}$,

where $A$ is the cross sectional area of the groove. The pressure gradient can be approximated as,

$\frac{d P}{d z} \simeq-\frac{\sigma}{\ell_{\text {eff }}}\left(\frac{1}{R_{\text {beg }}}-\frac{1}{R_{\text {end }}}\right)$,

where $\sigma$ is the surface tension, $R_{b e g}$ and $R_{\text {end }}$ are the radii of curvature at the beginning and at the end of effective length sections, respectively. The flow inside the channel is laminar resulting in

$\bar{U} \sim w h \frac{d P}{d z} \sim \frac{w h}{\ell_{\text {eff }}}\left(\frac{1}{R_{\text {beg }}}-\frac{1}{R_{\text {end }}}\right)$

and the liquid flow rate inside the channel, 


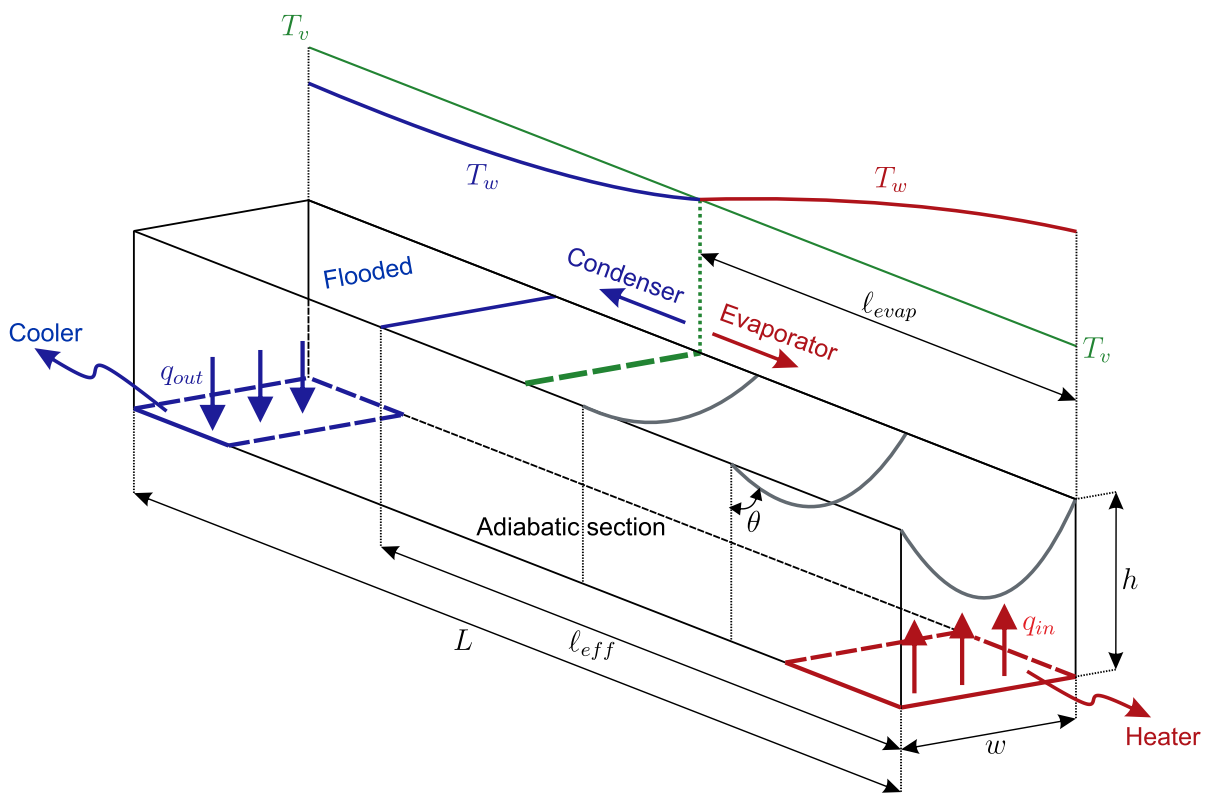

Fig. 1. Heat transfer and flow geometry in a single groove.

$\dot{m}_{\text {flow }} \sim w^{2} h^{2} \frac{d P}{d z} \sim w^{2} h^{2} \frac{\left(1 / R_{\text {beg }}-1 / R_{\text {end }}\right)}{\ell_{\text {eff }}}$.

In most cases $R_{\text {beg }} \rightarrow \infty$ due to a $90^{\circ}$ edge angle between the liquid and groove surface, particularly at the end of the flooded region. Invoking the geometric relation between the edge angle, the groove width and the radius of curvature,

$\dot{m}_{\text {flow }} \sim w^{2} h^{2} \frac{\cos \theta_{\text {beg }}-\cos \theta_{\text {end }}}{w \ell_{\text {eff }}} \sim \frac{w h^{2}}{\ell_{\text {eff }}}\left(\cos \theta_{\text {beg }}-\cos \theta_{\text {end }}\right)$

$\dot{m}_{\text {flow }} \sim \frac{w h^{2}}{\ell_{\text {eff }}}\left(\cos \theta_{\text {beg }}-\cos \theta_{\text {end }}\right)$.

Evaporation occurs due to the temperature difference between the solid and vapor, along the length of the evaporator. Majority of evaporation is in the micro region near the contact line [29,42]. The length of the micro region or similarly the rate of the evaporation, is a strong function of the edge angle [43]. Estimation of the evaporating mass flow can be given as follows:

$\dot{m}_{\text {evap }} \sim \ell^{*} \ell_{\text {evap }} \Delta T$.

In this expression, $\ell^{*}=\ell^{*}(\theta)$ is the micro region length and $\Delta T$ is the average temperature difference between the solid and vapor in the evaporator. The ratio of flow mass to evaporating mass is unity, and this ratio can be expressed as,

$\frac{\dot{m}_{\text {flow }}}{\dot{m}_{\text {evap }}} \sim \frac{w h^{2}}{\ell_{\text {eff }} \ell^{*} \ell_{\text {evap }} \Delta T}\left(\cos \theta_{\text {beg }}-\cos \theta_{\text {end }}\right)$.

In the current study, all heat pipes have grooves with square cross sections, i.e., $w=h$. Nevertheless, to discuss the effect of groove density on the results the two parameters that define the depth and width of the grooves are kept separate.

\section{Materials and methods}

Four flat grooved heat pipes with different groove specifications, namely G-200, G-400, G-800, G-1600 (the number indicating the groove width), are fabricated in the current work. Table 2 shows the groove specifications of the fabricated heat pipes. The length of the grooves are $100 \mathrm{~mm}$. One key parameter for the ther- mal characterization of a heat pipe is the groove density, which is defined as the number of grooves per unit width $(\mathrm{mm})$. The values of groove density are also listed in the table.

\subsection{Fabrication of the metal base}

The metal base is a $5 \mathrm{~mm}$-thick piece of aluminum on which the grooves are machined. The first step in its fabrication process is the machining of a groove for an o-ring to seal the test section. Next, a recess of depth $1 \mathrm{~mm}$ is machined on it to place the vacuum valve $23 \mathrm{~mm}$ off the grooves, in order not to block the view of their entire length. At the bottom side of the metal base, then, a rectangular recess of dimensions $100 \mathrm{~mm} \times 23 \mathrm{~mm}$ is machined $1 \mathrm{~mm}$ deep helping in placement of heater and cooler exactly under the grooves. On the center line of the recess, five rectangular holes of depth $0.4 \mathrm{~mm}$ with spacing of $10 \mathrm{~mm}$ are machined to attach thermocouples. Lastly, the fabrication of the grooves are performed by a 3-axis micro-machining center (PROINO Z3X Micro Maker) with an accuracy of $\pm 5 \mu \mathrm{m}$. The machining process has two major steps: (i) machining a rectangular recess with area of $103 \mathrm{~mm} \times 23.2 \mathrm{~mm}$ performed by a $1.2 \mathrm{~mm}$ cutting tool, feed rate of $2.5 \mathrm{~mm} / \mathrm{min}$ and rotational speed of $25,000 \mathrm{rpm}$ and (ii) machining of the grooves on the surface of the rectangular recess with the following machining parameters:

- G-200: $0.2 \mathrm{~mm}$ tool, $1.0 \mathrm{~mm} / \mathrm{min}$ feed rate, $30,000 \mathrm{rpm}$ rotational speed

- G-400: $0.4 \mathrm{~mm}$ tool, $1.0 \mathrm{~mm} / \mathrm{min}$ feed rate, $30,000 \mathrm{rpm}$ rotational speed

- G-800: $0.8 \mathrm{~mm}$ tool, $2.5 \mathrm{~mm} / \mathrm{min}$ feed rate, $25,000 \mathrm{rpm}$ rotational speed

- G-1600: $1.2 \mathrm{~mm}$ tool, $2.5 \mathrm{~mm} / \mathrm{min}$ feed rate, 25, $000 \mathrm{rpm}$ rotational speed

The rectangular recess creates a space available for the vapor flow during the experiments. The depth of the recess is $2.5 \mathrm{~mm}$ for all cases except G-1600 which is $1.4 \mathrm{~mm}$. These dimensions result in a distance of $0.9 \mathrm{~mm}, 0.7 \mathrm{~mm}, 0.3 \mathrm{~mm}$ and $0.6 \mathrm{~mm}$ between the thermocouples and bottom of the grooves, respectively for the heat pipes G-200 through G-1600. Following the 
Table 2

Groove specifications of four heat pipes.

\begin{tabular}{|c|c|c|c|c|c|}
\hline & \# of grooves & $\begin{array}{c}\mathrm{W} \\
{[\mathrm{mm}]}\end{array}$ & $\begin{array}{c}\mathrm{H} \\
{[\mathrm{mm}]}\end{array}$ & $\begin{array}{c}\mathrm{F} \\
{[\mathrm{mm}]}\end{array}$ & $\begin{array}{c}\text { Groove density } \\
\text { \# of grooves per mm }\end{array}$ \\
\hline G-200 & 50 & 0.2 & 0.2 & 0.2 & 2.50 \\
\hline G-400 & 26 & 0.4 & 0.4 & 0.4 & 1.25 \\
\hline G-800 & 13 & 0.8 & 0.8 & 0.8 & 0.63 \\
\hline G-1600 & 7 & 1.6 & 1.6 & 1.6 & 0.31 \\
\hline
\end{tabular}

machining, the metal pieces are soft-polished and ultrasonically cleaned to remove machining burr at all edges. Prior to the assembly, all metal pieces are washed by soap and IPA, rinsed with DI water and blow-dried. The detailed dimensions of the metal bases and locations of the o-ring, heater, cooler and thermocouples are shown in Fig. 2.

The fabricated pieces together with the grooves profile are shown in Fig. 3. The grooves profiles are also investigated with a 3D Laser Scanning Confocal Microscope (VK-X100, KEYENCE Corp.). The microscope image of the grooves profiles are also provided in the figure. Moreover, the surface roughness of the bottom surface of the grooves and top fin surfaces are measured at five different locations and the average values are reported in Table 3. According to the measurements, no significant variation is observed on the machining quality of the pieces. Hence, the effect of surface roughness on the comparison between the different groove widths is eliminated, and any possible effect of surface roughness on thermal performances is not considered.

\subsection{Heat pipe assembly}

The heat pipe assembly consists of layers of a metal base, an oring and a transparent plexiglas cover screwed together as seen in Fig. 4. The o-ring is of Viton type of durometer A75, specified for high vacuum purposes. The top cover is fabricated out of plexiglas to visualize the evaporation and condensation inside the heat pipe and to enable the measurement of the amount of the working fluid inside the heat pipe, as well as the location and extent of dryout.

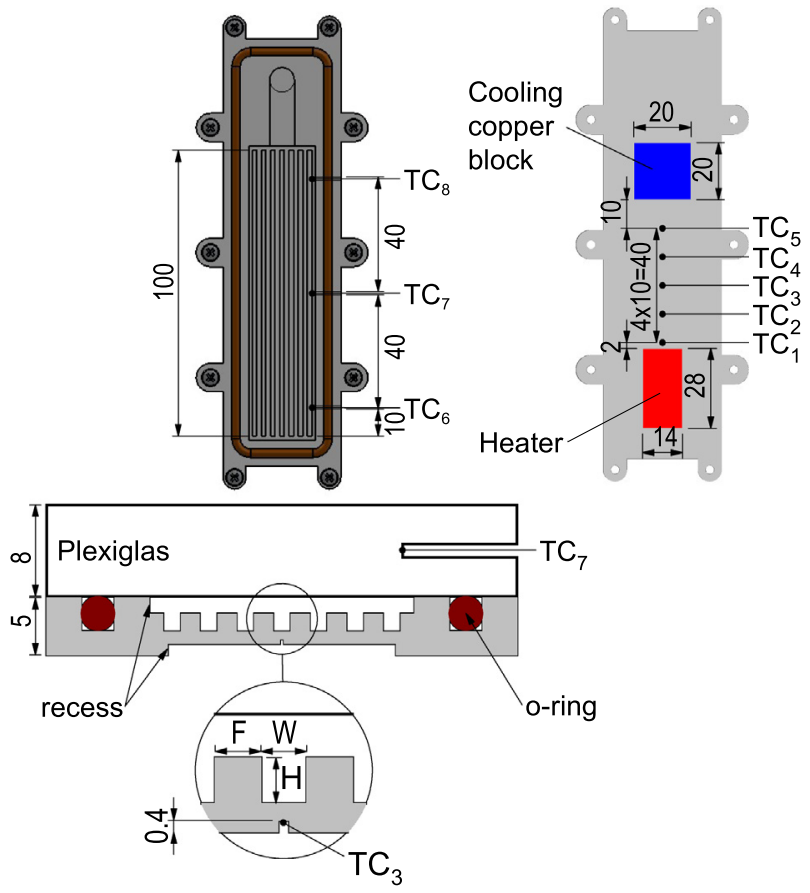

Fig. 2. Top, bottom and mid cross-sectional views of heat pipe G-1600 (all units are in $\mathrm{mm}$ ).
The top, bottom and mid cross-sectional views of heat pipe G1600 can be seen in Fig. 2 as an example. Except the groove specifications listed in Table 2, all other dimensions are the same for the heat pipes.

\subsection{Heating, cooling units and temperature measurements}

The heater used in the experiments is an electric resistance (ARCOL HS25 2R F) with peak power of $25 \mathrm{~W}$. Considering its surface area in contact with the bottom of the heat pipes, it is capable of introducing heat fluxes up to approximately $6 \mathrm{~W} / \mathrm{cm}^{2}$. The current passes the heater is measured with a power supply, and the voltage is measured with a voltmeter at two sides of the heater. To cool down the heat pipes, a cylindrical copper block of height $100 \mathrm{~mm}$ with top surface of square cross-section of $20 \mathrm{~mm} \times 20 \mathrm{~mm}$ is in touch with the bottom of the aluminum base. The copper block is submerged $90 \mathrm{~mm}$ in a water reservoir with continuous flow of cold tap water. The water flow rate for all of the experiments is kept between 1.6 to $1.8 \mathrm{~L} / \mathrm{min}$. It is worth mentioning that to avoid thermal contact resistance in the contact areas of the heat pipes with the heater and the copper block, silicon thermal paste is applied all over the contact surfaces. For temperature reading purposes, five T-type thermocouples are embedded into the metal base at desired locations between the heater and cooler. In addition, three thermocouples are placed at the half thickness of the plexiglas cover. The locations of all the thermocouples together with the heater and cooler are illustrated in Fig. 2. At the beginning of each test, temperatures of all surface thermocouples are measured for approximately 15 min with the setup insulated, and individual thermocouples are calibrated using the average temperature. The uncertainty of the measurement of the temperature differences are estimated to be $\pm 0.1 \mathrm{deg} C$ with a $95 \%$ confidence interval.

\subsection{Experimental setup and procedure}

The operational temperature range of a heat pipe is a key factor in the selection of proper working fluid. Some other parameters that need to be considered include compatibility with wall and wick material (i.e. wettability), high latent heat of vaporization and high surface tension $[44,45]$. Considering compatibility, IPA is selected as the working fluid due to its wettability characteristic with aluminum [45]. Fig. 4 illustrates the components of the heat pipe assembly. In order to eliminate the environmental effects on the performance of the heat pipes, all exterior surfaces of the metal base and the plexiglas cover are insulated, and the insulation of the top surface of the plexiglas is only removed temporarily to visually observe the evaporation and condensation inside the heat pipe, measure the amount of IPA and locate the extent of dryout. In order to keep the heat pipe at a fixed horizontal orientation during the experiments, it is screwed to an acrylic holder. Fig. 5 shows the assembled components on the setup bench. The heat pipe is intended to operate using the vapor and liquid phases of a pure substance at equilibrium. The presence of even minute quantities of any other fluid adversely affects the thermal performance, therefore the removal of air from the system before charging with the working fluid is crucial. Moreover, any air dissolved in the liquid 


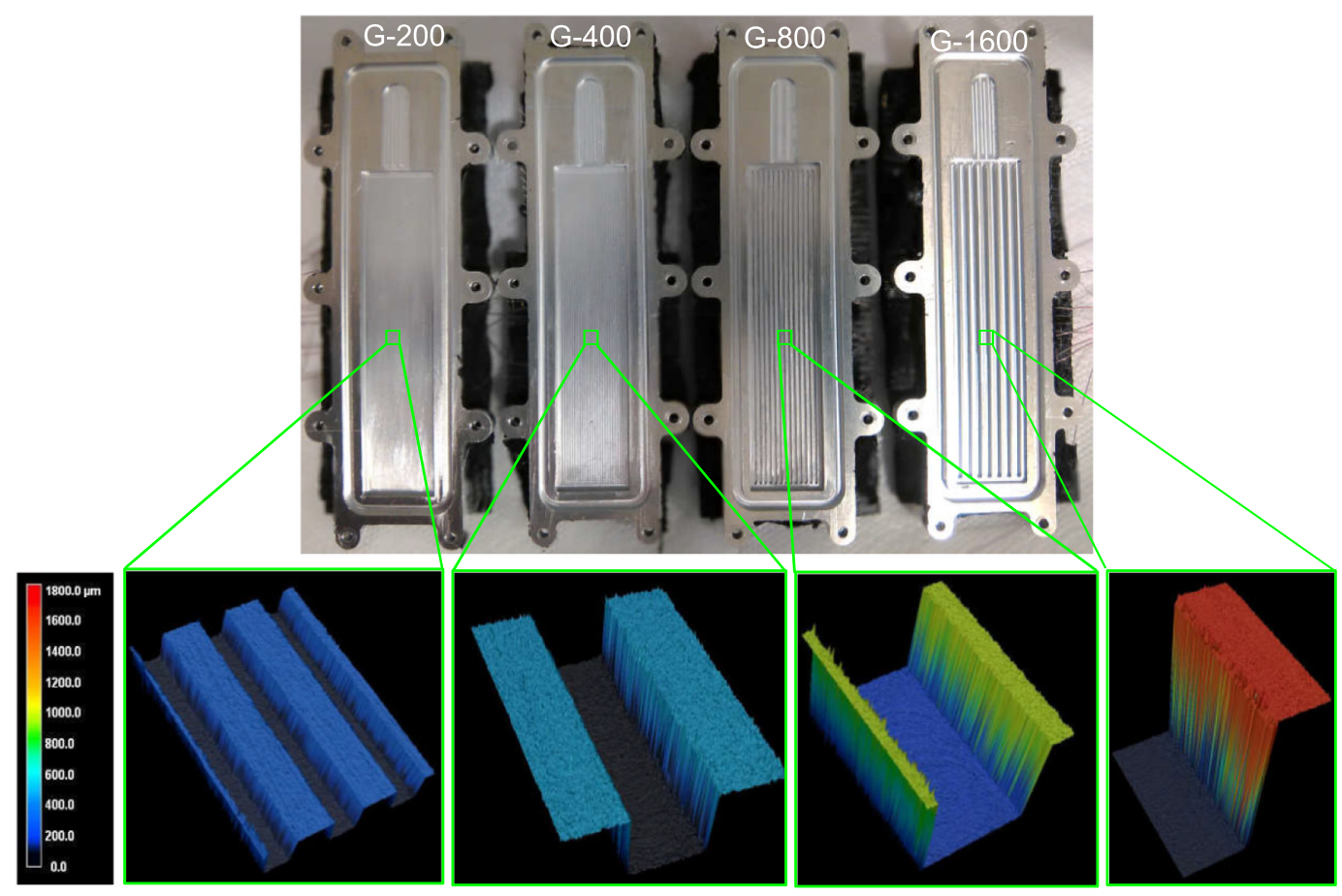

Fig. 3. Fabricated metal pieces and the groove profiles.

Table 3

Average surface roughness of bottom of the grooves and the fins.

\begin{tabular}{lcc}
\hline & Bottom surface of the grooves $[\mu \mathrm{m}]$ & Fin surface $[\mu \mathrm{m}]$ \\
\hline G-200 & 0.37 & 0.50 \\
G-400 & 0.46 & 0.67 \\
G-800 & 0.54 & 0.73 \\
G-1600 & 0.36 & 0.50 \\
\hline
\end{tabular}

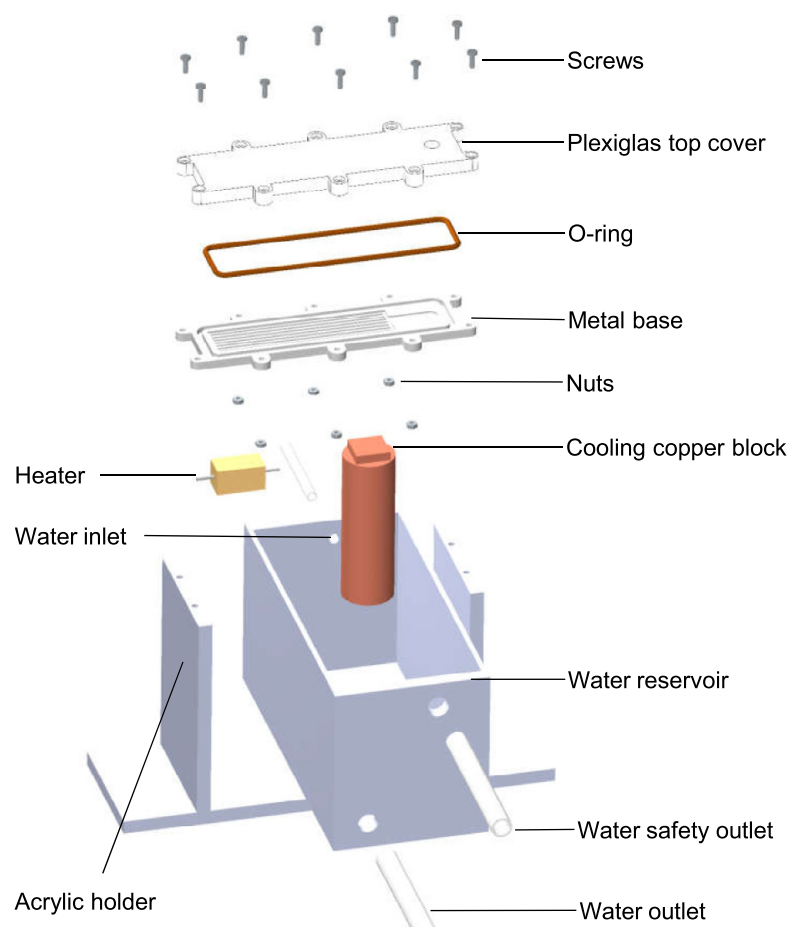

Fig. 4. Components of the experimental setup.
IPA must also be eliminated. To achieve this, IPA is degassed for 15 minutes under 0.2 bar vacuum prior to charging in the heat pipe. Fig. 6 shows the components used in the vacuuming process of the heat pipes. All the valves and connections used in this work are gas tight to ensure no air penetration to the heat pipe. The experimental procedure is as follows:

1. All space in the heat pipe is filled with IPA (the so called "fullyflooded" operating condition that corresponds to the highest values of filling ratio).

2. Four different heating conditions corresponding to input heat fluxes of $2.1,3.2,4.2$ and $5.3 \mathrm{~W} / \mathrm{cm}^{2}$ are applied to the heat pipe and transient temperatures are recorded until steady-state is reached.

3. The heater is turned off and the cooling water reservoir is drained. When the system reaches thermal equilibrium with the environment the heat pipe is tilted to a vertical orientation, some IPA is extracted from the heat pipe for the new operating point, and the new IPA extent is measured. Before each IPA removal, the pressure inside the cavity is less than $7.5 \times 10^{-2}$ Torr assuring that no air is present in the connections or pipes; i.e. all pipes and connections beyond V3 in Fig. 6 are subject to vacuum conditions.

4. The procedure is repeated starting from (2) until the heat pipe is entirely drained of IPA (the so called "dry" operating condition that corresponds to the filling ratio of zero).

Fig. 7 shows the transient and steady-state temperature readings of thermocouples for different filling ratios and heat inputs for a sample run of heat pipe G1-200. The duration of the test depends on the number of filling ratios realized and it differs for heat pipes with different groove density. On the average, each experiment takes two days to complete in two 10-12 h sessions. There is a limitation in the range of experiments due to failure. For some filling ratios-especially near fully-flooded and dry operating conditions with higher heat inputs-temperatures peak and exceed $60^{\circ} \mathrm{C}$. In such a case, the plexiglas is damaged and cracking or surface crazing 


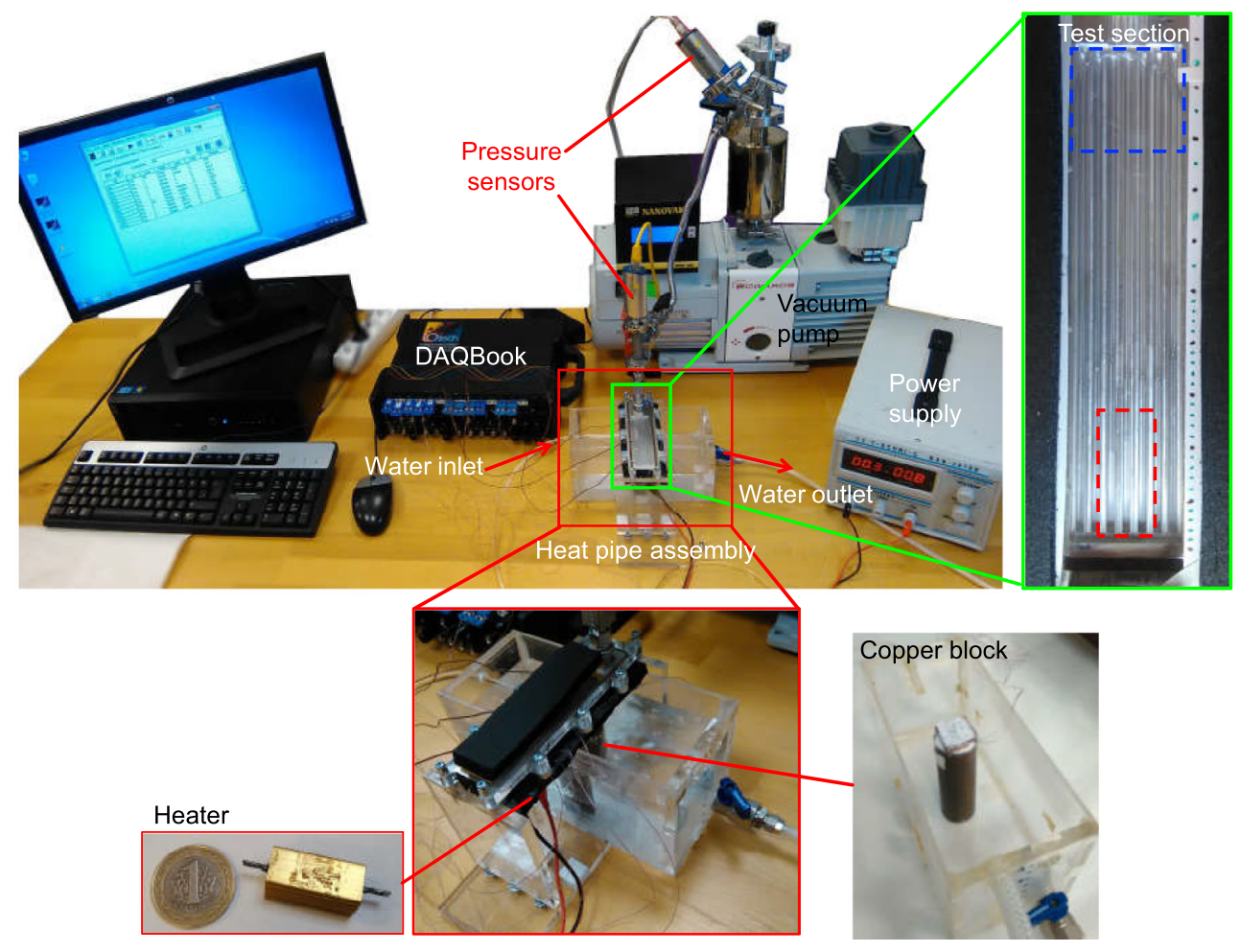

Fig. 5. Experimental setup table.

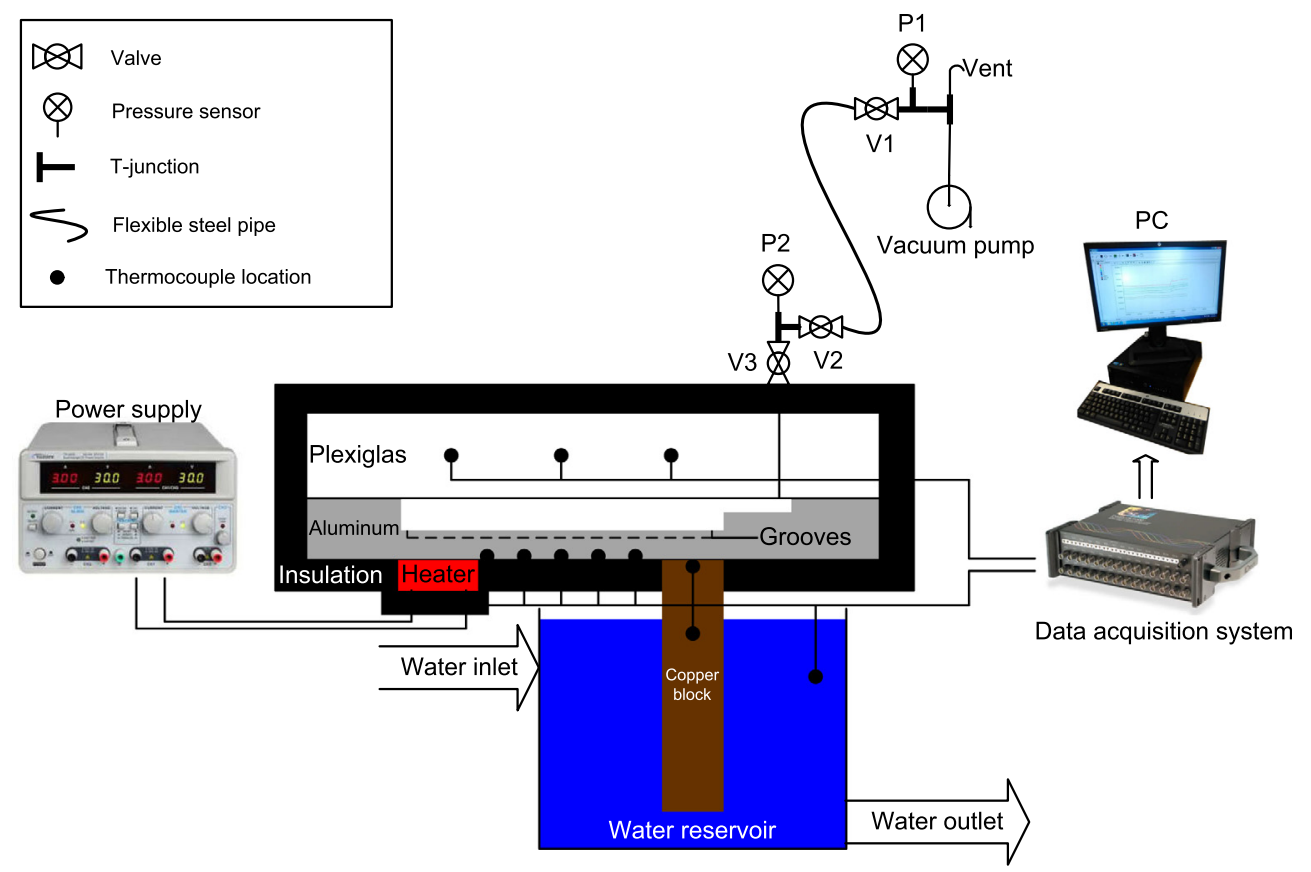

Fig. 6. Schematics of the vacuuming station for the heat pipes (Not to scale).

occurs due to its low chemical resistance when exposed to high temperature IPA. In order to avoid failure, only a safe operating zone is exercised, where peak plexiglas temperatures are not allowed to go beyond the failure limit. This reflects itself in the results, where the corresponding data points are absent in Table 4 .
An uncertainty analysis is performed considering the elemental uncertainties of measurement devices. These are reflected in the reported results of filling ratios and heat pipe effectiveness values. The uncertainties associated with actual temperature measurements are $\pm 0.1{ }^{\circ} \mathrm{C}$, these are not shown in figures. 


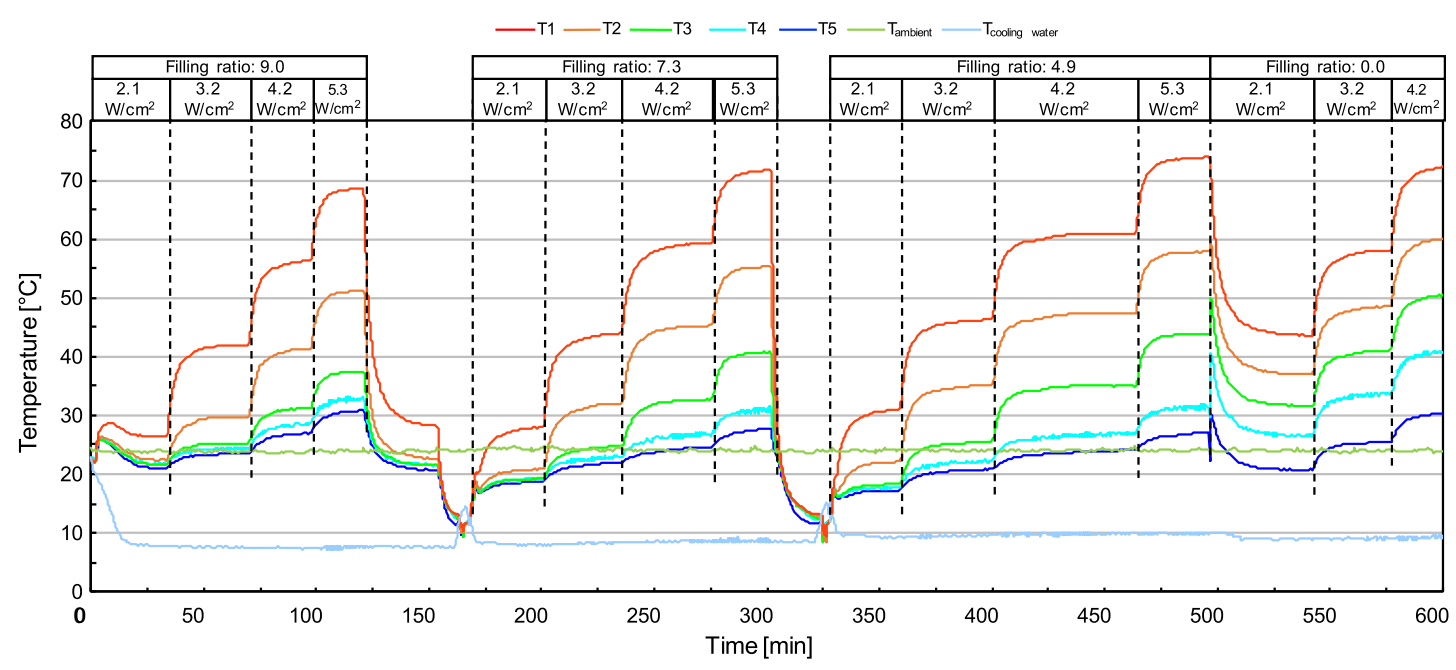

Fig. 7. Different operating conditions of heat pipe G-200.

\section{Thermal Performance Indicators}

Thermal performance is a function of design as well as operating parameters, and for a specific design, the amount of working fluid in the heat pipe significantly affects its performance $[46,47]$. The filling ratio is defined as the ratio of total volume of working fluid to the total volume of the grooves, i.e. $V_{\text {fluid }} / V_{\text {groove }}$. A fullyflooded heat pipe has a filling ratio larger than unity, and the filling ratio corresponding to a fully-flooded operation is a function of groove width. A filling ratio of zero corresponds to an empty heat pipe (i.e. a dry operation). Three performance indicators are used in the assessment of heat pipe performance. Two are temperature differences in the system and one is the effectiveness of the heat pipe. The filling ratio which results in the best thermal performance based on the relevant indicator is defined as the "optimum" operating point for a given heat flux value.

\subsection{Temperature difference and peak temperature}

The use of phase change heat transfer allows the heat pipes to operate with lower temperatures in the system, as well as lower temperature differences between the hot and cold junctions. In industrial applications, electronic component cooling requirements dictate the system to operate below temperatures that would result in component failure. On the other hand, a better performing heat pipe, in general, is a device which transfers the same amount of heat with the minimum temperature difference between the hot and cold junctions or with a minimum value of peak temperature in the system.

\subsection{Heat pipe effectiveness}

Effective thermal conductivity and thermal resistance are commonly used to quantify the performance of a heat pipe. These parameters are meaningful when the separation between the heat source and sink is large, resulting in an effectively 1-D heat conduction in the base metal; however these parameters may not effectively describe thermal performance when the distance between the two approaches zero. A performance indicator that would be appropriate for the current set of experiments could be the ratio of the heat transferred through phase change to conduction-in essence an effectiveness-however, this is not a possible measurement in the current set-up, and a prohibitively difficult measurement in general. Therefore, a new indicator, the heat pipe

Table 4

Variation of temperature difference and peak temperature with filling ratio and heat flux for different groove sizes.

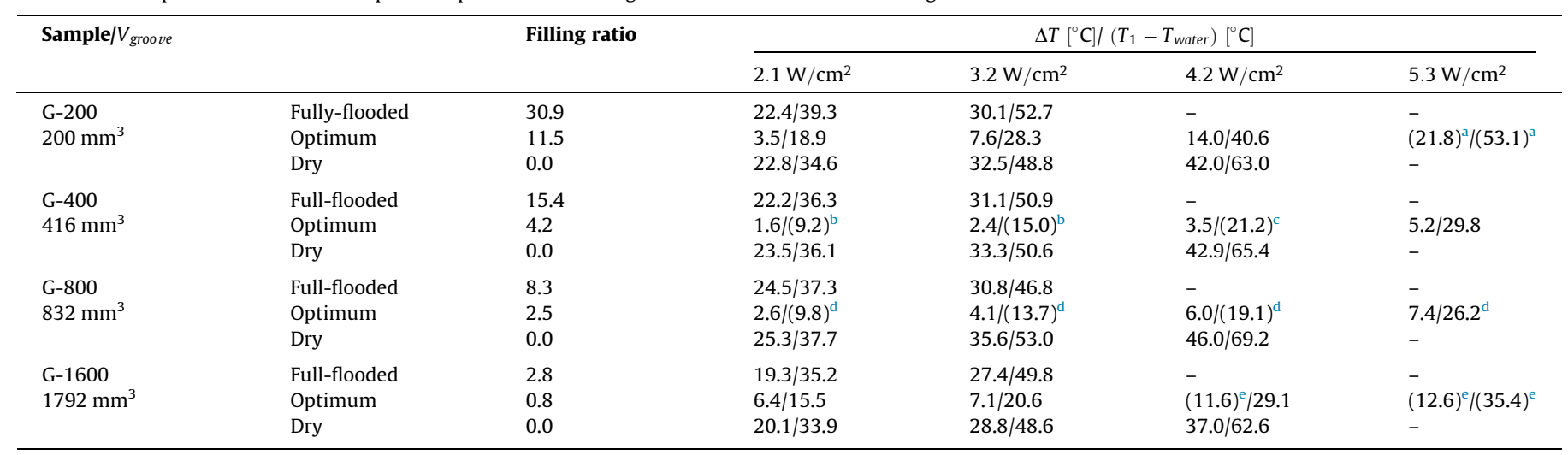

a Filling ratio 14.9 .

b Filling ratio 1.8 .

c Filling ratio 3.0.

${ }^{\mathrm{d}}$ Filling ratio 1.9.

e Filling ratio 1.1 
effectiveness is introduced and used in the assessment of thermal performance in the current heat pipes. The effectiveness, $\varepsilon_{h p}$, is defined as,

$\varepsilon_{h p} \equiv \frac{\Delta T_{\text {dry }}}{\Delta T_{\text {operating }}}$

where $\Delta T_{d r y}$ and $\Delta T_{\text {operating }}$ are the temperature differences between the heat source and sink regions for the dry and heat pipe operating conditions, respectively. The temperature difference between the heat source and the sink is at a maximum during dry operation and reaches a minimum at the optimum operating point. Therefore, the effectiveness will be unity for dry operation-heat transfer through heat conduction in the metal alone-and will exceed unity with the start of phase change heat transfer. The effectiveness can be related to the effective thermal conductivity or thermal resistance concepts used in the literature. The reason for this new indicator of heat pipe performance is explained in the following sections, as results will show this parameter to be a function of not only the filling ratio but power input as well.

\section{Results and discussion}

\subsection{Temperature difference and peak temperature}

The two most distant thermocouples $T C_{1}$ and $T C_{5}$ are closest to the heat sink and source (Fig. 2). The temperature difference between the two, $\Delta T \equiv T_{1}-T_{5}$, is plotted in Fig. 8 at different filling ratios and input heat flux values. The highest value of the filling ratio in each graph corresponds to a fully-flooded while a filling ratio of zero corresponds to dry operation. All heat pipes show a similar variation of temperature difference as a function of filling ratio. When fully-flooded, the entire heat load is transferred through the aluminum base, IPA and the plexiglas top cover with thermal conduction. The bulk of the heat is transferred in the aluminum, due to negligible thermal conductivity values of IPA and plexiglas $(0.14 \mathrm{~W} / \mathrm{m} \mathrm{K}$ and $0.18 \mathrm{~W} / \mathrm{m} \cdot \mathrm{K}$, respectively) compared to that of aluminum $(140 \mathrm{~W} / \mathrm{m} \mathrm{K})$. As IPA is removed from the heat pipe and the filling ratio reduced, phase change heat transfer begins and the temperature difference along the heat pipe drops. This effect intensifies with successive removals of IPA, reaching a minimum value of temperature difference. At this point, the heat transfer via phase change is at a maximum and conduction at a minimum. Any further removal of IPA results in an increase in $\Delta T$, effectively a reduction in heat transferred through phase change and an increase in thermal conduction through the solid. This trend continues until the heat pipe cavity is totally void of any fluid-i.e. it is entirely dry-and the heat transfer is due to heat conduction in the metal base alone.

The significance of the two temperature differences used as performance indicators differ in specific applications. When the application involves maximizing heat transfer from a constant temperature reservoir, the indicator $\Delta T$ is relevant, whereas in an application where the maximum allowable temperature in the system is a design criterion-i.e. in electronics cooling-the second temperature difference, $T_{1}-T_{\text {ambient }}$ is the relevant indicator. Fig. 9 shows the temperature differences between the first thermocouple $T C_{1}$ and the cooling water reservoir. This thermocouple being the closest to the heating unit records the highest temperature readings, which is of the highest temperature in the system. Comparing Figs. 8 and 9, it can be seen that the minimum value of temperature differences and peak temperatures occur at approximately the same filling ratios for all cases studied. These points where both temperature performance indicators are at a minimum are the optimum operating points. The filling ratios for which the heat pipes operate at minimum temperature difference are summarized in Table 4. The results also reveal that the operation of a heat pipe with high or very low filling ratios, away from the optimum, may be dominated by conduction alone with little heat transferred through phase change. In such a case, the device is operating at best marginally, at worst not at all as a heat pipe.

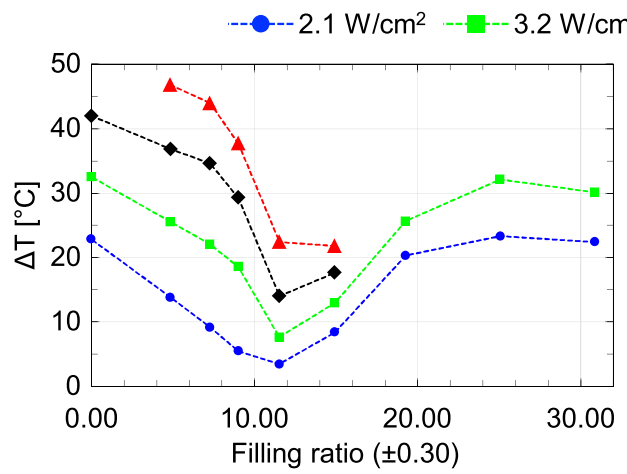

(a) G-200

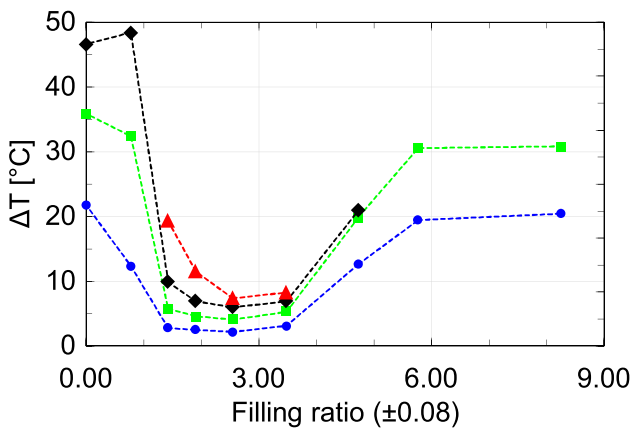

(c) G-800

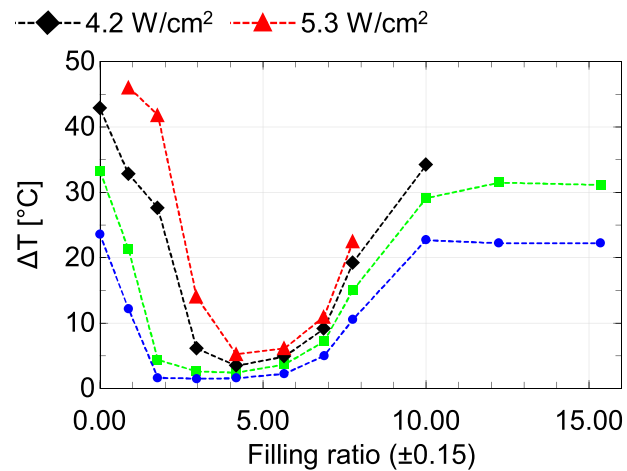

(b) G-400

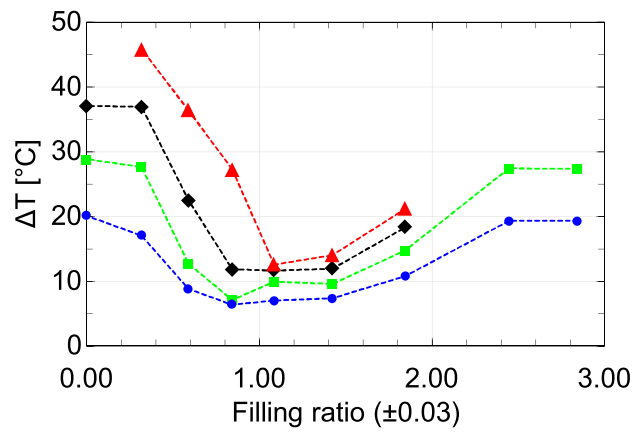

(d) G-1600

Fig. 8. Variation of $\Delta T$ with filling ratio for different heat flux values. 


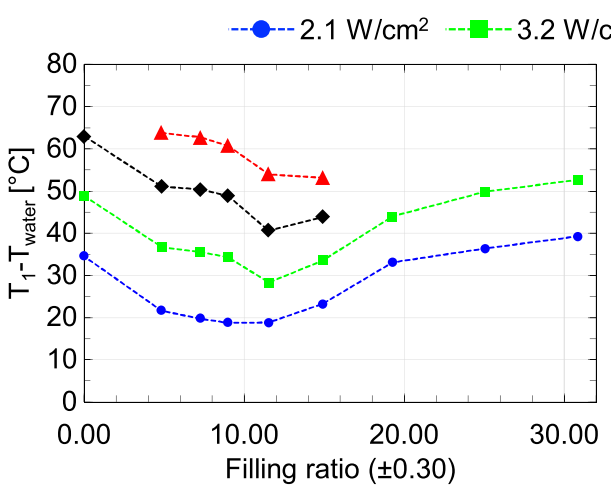

(a) G-200

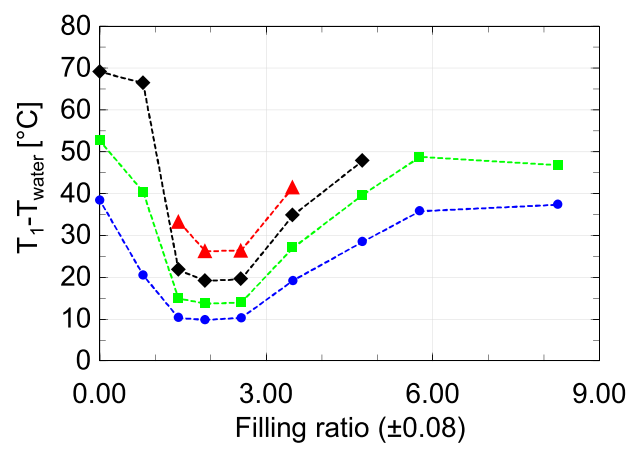

(c) $\mathrm{G}-800$

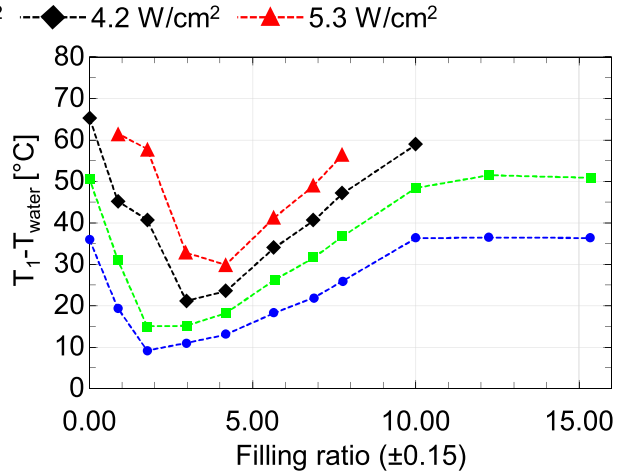

(b) G-400

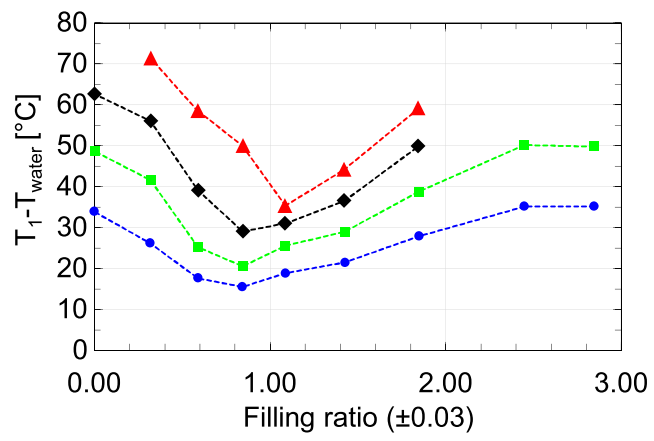

(d) G-1600

Fig. 9. Variation of $T_{1}-T_{\text {water }}$ with filling ratio for different heat flux values.

Unless observed visually, or a wide scan of filling ratios is covered experimentally, this operating regime cannot be argued to be a heat pipe.

\subsection{Heat pipe effectiveness}

The effectiveness of the heat pipe is a function of the filling ratio and heat input for a given design. The filling ratio is especially important, and an effectiveness value close to unity indicates that the heat pipe is actually not operating as it is supposed to, i.e. through phase change. The operating point where the effectiveness is at a maximum is desired, since this will result in the best possible use of a given design operating between two constant temperature reservoirs-enabling the maximum heat transfer. In the current study, however, the heater side experiences constant heat flux and the cooler is subjected to a convective boundary condition. As a result of this, for an identical heating power, different filling ratios result in different temperature differences. Since the length of the adiabatic section is nonzero, the temperature difference between the heater and cooler sections is an indication of the magnitude of the conduction heat transfer in the solid base. The metal base cross sectional areas are approximately identical for heat pipes G-200, G-400 and G-800 and larger for G-1600 due to manufacturing restrictions. Table 4 shows that for the same input power, heat pipes G-200, G-400 and G-800 experience approximately the same temperature differences for the dry cases in all heat fluxes, and G-1600 has a smaller temperature difference due to a larger cross sectional area. Therefore, it can be concluded that for the same heat input the three smaller grove heat pipes have the same heat conduction in the metal base. Because of this the effectiveness can be used as a metric to compare the thermal performance of two different heat pipes operating at the same load, or as a metric comparing the performance of the same heat pipe for different filling ratios. If one compares the ratio of the temperature differences to the heat input for the dry cases for the same heat pipes, in the current configuration it can be seen that the temperature difference, hence the effectiveness is a measure of the heat conducted in the base metal. For the G-200 case, for example, the ratio of input powers to temperature differences for the three reported heat loads are, $2.1: 22.8,3.2: 32.5$ and $4.2: 42.0$, respectively, enabling the usage of the effectiveness for the same heat pipe for different loads as well. It should be emphasized that the current definition of effectiveness may not be suitable when comparing geometrically identical heat pipes with different base materials, or different working fluids, since the operating regimes and the multi-dimensional nature of conduction in the base material may be substantially different so that any comparison may become invalid. Fig. 10 shows the variation of effectiveness with filling ratio. Comparing this figure with Fig. 8, the highest value of $\varepsilon_{h p}$ for each heat pipe corresponds to the filling ratio at which it has the lowest $\Delta T$ during its operation. The uncertainties in the measurements affect the location of peak effectiveness values. The filling ratio corresponding to maximum effectiveness for G-200, G400 and $\mathrm{G}-800$ are $11.5,4.2$ and 2.5 , respectively, for all the heat flux values. For $\mathrm{G}-1600$, this point lies in the approximate range of filling ratios, $0.8-1.4$ for all heat flux values accounting for experimental uncertainties.

When a heat pipe operates at the filling ratio on the onset of dryout, removal of additional working fluid results in a partial dryout, causing an increase in temperatures and a reduction in the amount of liquid flowing to the evaporator. As a consequence, some or all of the grooves become partially dry. This condition may result in a temperature jump at and in the near vicinity of the evaporator section. Moreover, once dryout initiates, increasing the heat input may lead it to extend further in the grooves. Fig. 11 shows the extent of dryout in four heat pipes. According to this figure, after onset, dryout extent increases with increasing heat input and decreasing filling ratio.

The effectiveness of G-1600 is independent of the heat flux whereas the others are strongly affected by the magnitude of the 


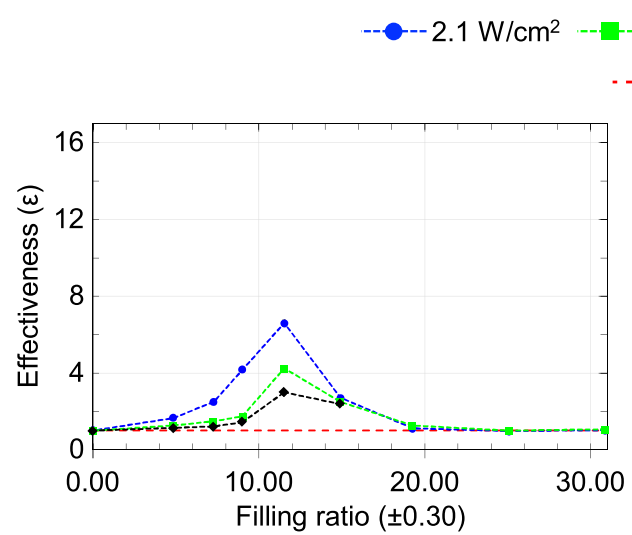

(a) G-200

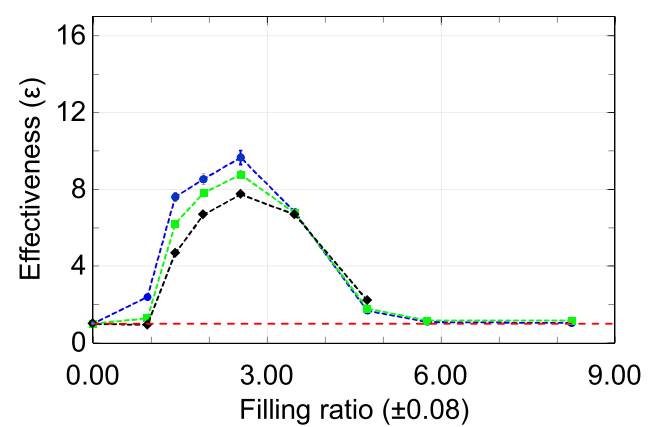

(c) G-800
$3.2 \mathrm{~W} / \mathrm{cm}^{2}-4.2 \mathrm{~W} / \mathrm{cm}^{2}$

$---\varepsilon=1.0$

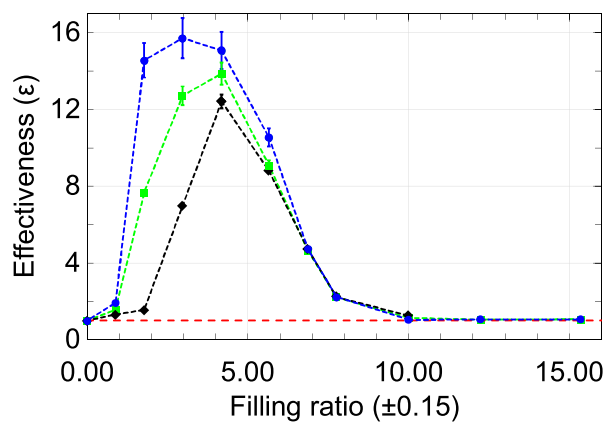

(b) $\mathrm{G}-400$

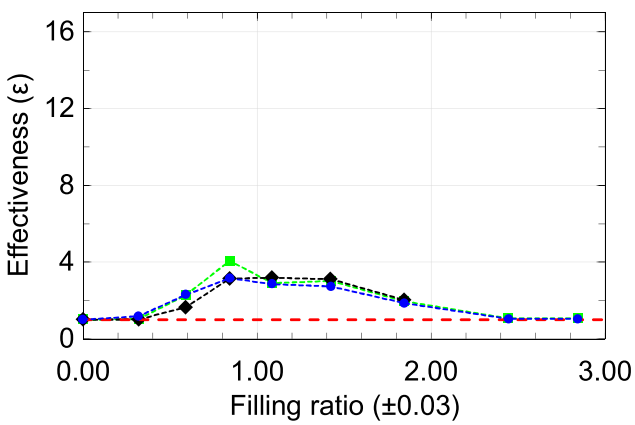

(d) G-1600

Fig. 10. Variation of effectiveness with filling ratio under different input heat fluxes.

heat flux. The sudden drop in the effectiveness near the optimum point can be attributed to two reasons. For filling ratios less than the value corresponding to optimum, the heat pipe operates progressively with increased dryout extent as the heat flux increases. For higher filling ratios, on the other hand, the effectiveness decreases due to a reduction in the contribution of phase change to heat transferred.

Fig. 10 shows an increasing trend of effectiveness values with decreasing groove width, (i.e. increasing groove density) for G400 to G-1600. The increase in the effectiveness from G-1600 to G-400 is expected, since heat transfer area for evaporation is predominantly near the contact line [29] within the groove and an increase in groove density increases the total area for evaporation enabling the heat pipe to carry the same evaporative heat load with lower temperature differences. For G-200, the trend is reversed and the effectiveness decreases. This is due to the presence of dryout in the G-200 for all heat flux values. Fig. 12 shows the variation of $\Delta T$ with filling ratio at the lowest heat flux for G$200, \mathrm{G}-400$ and G-800. In the case of G-400 and G-800, the minimum temperature difference is sustained in a range of filling ratios (i.e. a minimum temperature plateau), whereas for G-200, this is observed at a single point. As reported in Fig. 11, G-400 and G800 operate without any dryout, however G-200 operates with dryout in the neighborhood of the minimum temperature difference.

This suggests that for G-400 and G-800, the liquid film is present in the groove for all values of filling ratios. In general, this liquid film is assumed to attach to the upper corners of the grooves along the groove axis during the meniscus deformation. However, the presence of a twin menisci structure at the bottom corners was also reported prior to dryout [39]. Each inner corner meniscus contacts the wall and bottom of the groove with identical contact angles $(\alpha)$. Therefore, the capillary pumping of the liquid is gener- ated by the continuous shrinking of the inner corner menisci, instead of a varying edge angle [39]. In the evaporator region, the variation of the edge angle, $\theta$, from approximately $\pi / 2$ to $\alpha$ can be portrayed as shown in the inset of Fig. 12, where the linear variation of the edge angle is illustrative. This behavior can be explained considering parameters that affect the capillary flow and evaporation in the grooves. In this regime, the condenser surface is partially flooded, with the edge angle being equal to $\pi / 2$ at the beginning of the region where the flow starts. With decreasing fill ratio the effective flow length, $\ell_{\text {eff }}$, increases and to sustain the flow in the pipe-as given in Eq. (2.6)-the edge angle at the end, $\theta_{\text {end }}$, decreases. This trend continues until the edge angle reaches the contact angle. Before the onset of dryout, G-400 and G-800 operate along the full-length of the evaporator section; the evaporation capacity of the heat pipe is fully utilized, resulting in a lower temperature difference between the walls and the vapor to transfer the heat. G-200, on the other hand, is in the dryout regime, and the edge angle varies from $\pi / 2$ to the value of contact angle in a shorter distance due to the presence of a dried-out extent, effectively reducing the evaporation area. This, in turn, results in an increase in the temperature difference between the wall and vapor, thus increasing the minimum temperature difference. In this case, G-200 is operating in a different regime; with phase change in the presence of dryout. The underlying physics of this regime can be explained through the parameters that affect the ratio of mass flow rate and evaporative mass, given in Eq. (2.6). In this regime, there may still be excess liquid on the condenser top, resulting in reduced effective flow length and a corresponding higher pressure gradient, however, due to the decreased groove width $w$, the flow cannot sustain evaporation and the fluid recedes, reducing the effective flow length and increasing the pressure gradient until mass and evaporative flow rates balance. Since this balance occurs at a reduced evaporation length with dryout, a lesser amount of 


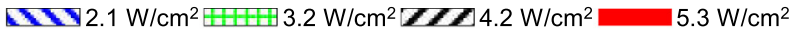

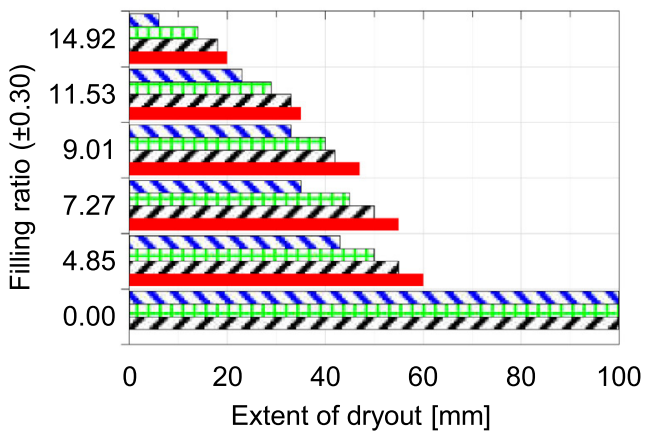

(a) G-200

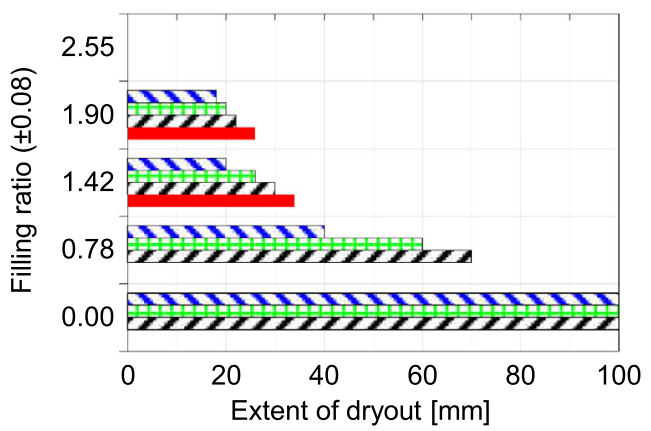

(c) G-800

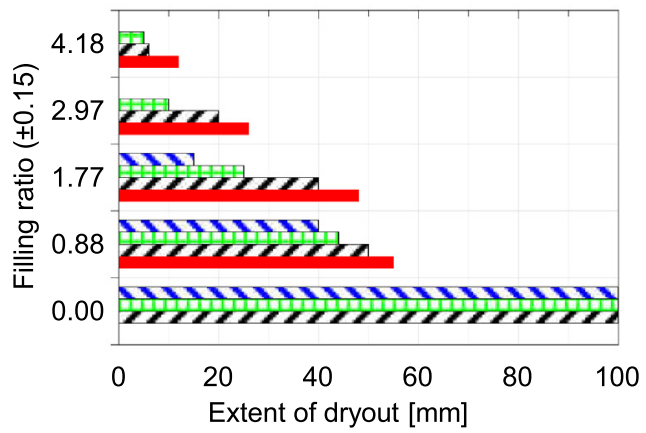

(b) G-400

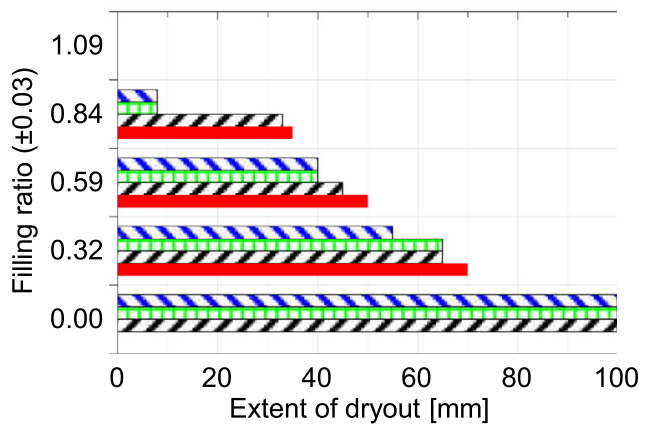

(d) G-1600

Fig. 11. Variation of dryout extent with filling ratio under different input heat fluxes.

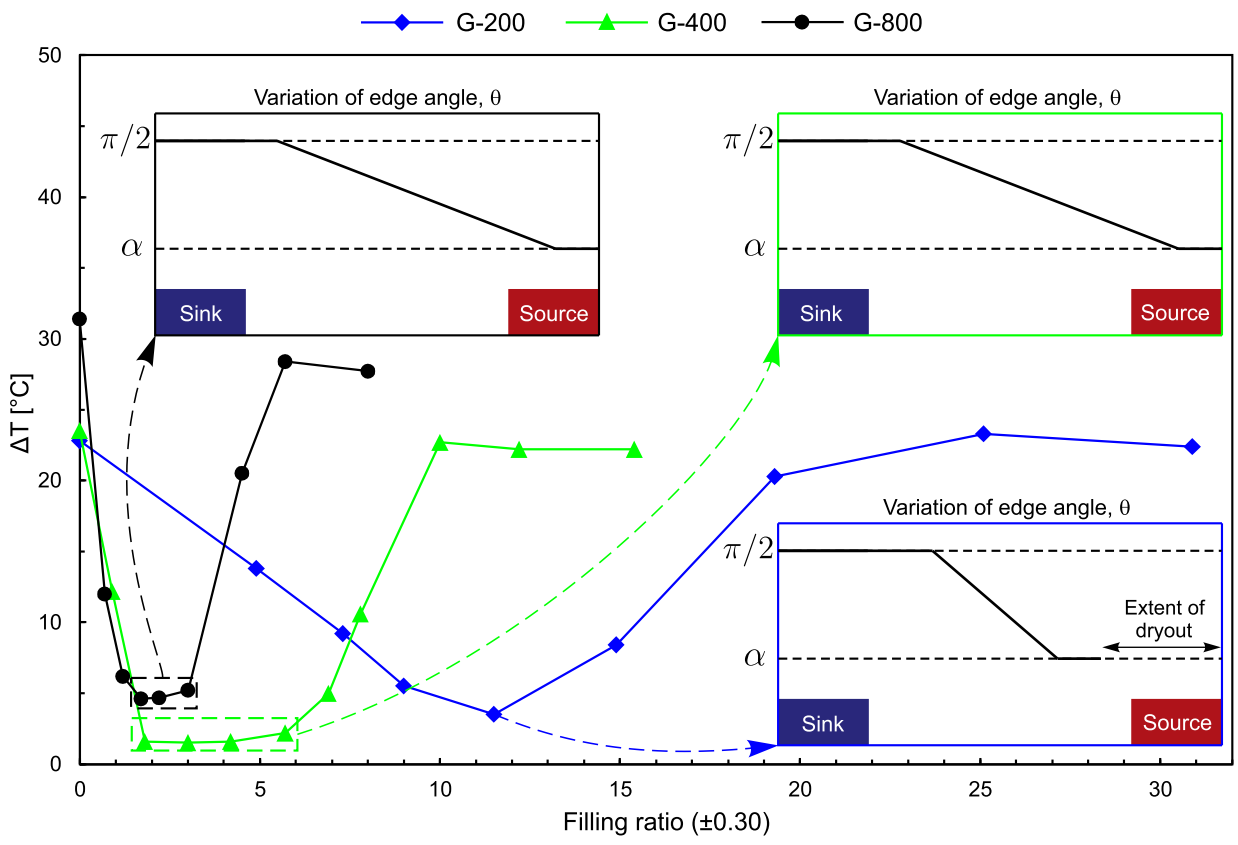

Fig. 12. Effect of presence of dryout on the performance indicator $\Delta T$ at the lowest heat flux $\left(2.1 \mathrm{~W} / \mathrm{cm}^{2}\right)$.

heat can be transferred through phase change, and the temperature difference between the evaporator and vapor must increase. This regime is regarded to be undesirable due to the absence of the minimum temperature plateau, since the system is prone to sudden temperature increases with any increase in heat flux during operation. Therefore, the performance parameters described above should not be interpreted alone but in conjunction with the presence or absence of dryout. It should be noted that the same operating regime is also observed for G-400, G-800 and G-1600 as seen in Fig. 8 where the minimum temperature plateau tends to disappear at higher heat flux values.

\section{Concluding remarks}

The effects of filling ratio, groove density and input heat flux on the thermal performance of flat grooved heat pipes are extensively 
studied. Four heat pipes with different groove densities are fabricated on aluminum and experiments carried out. The findings can be summarized as follows:

- All tested heat pipes are able to dissipate the input heat predominantly through phase change of the working fluid and thus operate as a heat pipe. It should be noted that unless confirmed through measurement or observation it is possible to operate the device mainly with heat conduction rather than phase change, in which case the device is, effectively, not a heat pipe.

- The indicator for the "optimum" operating point should be chosen according to the type of thermal boundary conditions and the desired output of the heat pipe. The filling ratios corresponding to the optimum operating point based on temperature differences and effectiveness, for which the temperature differences are at a minimum and effectiveness is at a maximum, are reported.

- Near the optimum operating point, dryout tendency increases with increasing groove density. Dryout tendency also increases with increasing heat flux. For low heat fluxes the devices operate in a regime where no dryout is present, and the indicators, although a function of filling ratio, follow a flat profile in midrange, rendering them comparatively insensitive to filling ratio. For higher heat flux values, on the other hand, dryout settles in, the plateau in the indicator-filling ratio variation shrinks to a single point and vanishes, and the device operates in a different regime. Although functional, this modus operandi is judged to be undesirable, since the device may become susceptible to sudden increases in temperature with fluctuations in heat input.

- As long as the heat pipe operates without any dryout, the heat pipe effectiveness increases with groove density, rendering narrower grooved pipes preferable; and it drops with increasing heat flux when the dryout operating regime appears, restricting the use of narrow grooves. Moreover, narrow grooves are not preferable vis-à-vis the manufacturing time and cost, therefore the groove size needs to be selected accordingly for a given application.

\section{Acknowledgments}

This study is financially supported by the Turkish Scientific and Technical Research Council, under Grant No. 213M351. Authors would like to thank Mr. Fatih Altunel for his guidance during the machining of the metal pieces.

\section{References}

[1] Suresh V. Garimella, Tannaz Harirchian, Encyclopedia of Thermal Packaging: volume 1: Microchannel Heat Sinks for Electronics Cooling, World Scientific, 2013.

[2] David Reay, Ryan McGlen, Peter Kew, Heat Pipes: Theory, Design and Applications, Butterworth Heinemann, 2013.

[3] X. Yang, Y.Y. Yan, D. Mullen, Recent developments of lightweight, high performance heat pipes, Appl. Therm. Eng. 33 (2012) 1-14.

[4] Omer A. Alawi, Nor Azwadi Che Sidik, H.A. Mohammed, S. Syahrullail, Fluid flow and heat transfer characteristics of nanofluids in heat pipes: a review, Int. Commun. Heat Mass Transf. 56 (2014) 50-62.

[5] Hamidreza Shabgard, Michael J. Allen, Nourouddin Sharifi, Steven P. Benn, Amir Faghri, Theodore L. Bergman, Heat pipe heat exchangers and heat sinks: opportunities, challenges, applications, analysis, and state of the art, Int. J. Heat Mass Transf. 89 (2015) 138-158.

[6] H.T. Lim, S.H. Kim, H.D. Im, Kwang H. Oh, S.H. Jeong, Fabrication and evaluation of a copper flat micro heat pipe working under adverse-gravity orientation, J. Micromech. Microeng. 18 (10) (2008) 105013.

[7] Reinhard Schlitt, Performance characteristics of recently developed highperformance heat pipes, Heat Transf. Eng. 16 (1) (1995) 44-52.

[8] Cem Ömür, A Bilge Uygur, H. Gürgüç Işık, İlhami Horuz, Manufacturing phase embedded design optimization of extruded heat pipes for space applications, Appl. Therm. Eng. 126 (2017) 436-446.
[9] Cem Ömür, A Bilge Uygur, İlhami Horuz, H. Gürgüç Işık, Sadık Ayan, Murat Konar, Incorporation of manufacturing constraints into an algorithm for the determination of maximum heat transport capacity of extruded axially grooved heat pipes, Int. J. Therm. Sci. 123 (2018) 181-190.

[10] X. Xu, V.P. Carey, Film evaporation from a micro-grooved surface-an approximate heat transfer model and its comparison with experimental data, J. Thermophys Heat Transf. 4 (4) (1990) 512-520.

[11] A.R. Anand, A.J. Vedamurthy, S.R. Chikkala, S. Kumar, D. Kumar, P.P. Gupta Analytical and experimental investigations on axially grooved aluminumethane heat pipe, Heat Transf. Eng. 29 (4) (2008) 410-416.

[12] R. Hopkins, A. Faghri, D. Khrustalev, Flat miniature heat pipes with micro capillary grooves, J. Heat Transf. 121 (1) (1999) 102-109.

[13] A.J. Jiao, H.B. Ma, J.K. Critser, Evaporation heat transfer characteristics of a grooved heat pipe with micro-trapezoidal grooves, Int. J. Heat Mass Transf. 50 (15) (2007) 2905-2911.

[14] D. Plesch, W. Bier, D. Seidel, K. Schubert, Miniature heat pipes for heat removal from microelectronic circuits, in: Proceedings of ASME Annual Meeting. Atlanta: GA, 1991.

[15] Y. Cao, J.E. Beam, B. Donovan, Air-cooling system for metal oxide semiconductor controlled thyristors employing miniature heat pipes, J Thermophys. Heat Transf. 10 (3) (1996) 484-489.

[16] Xue Fei Yang, Zhen-Hua Liu, Jie Zhao, Heat transfer performance of a horizontal micro-grooved heat pipe using $\mathrm{CuO}$ nanofluid, J. Micromech. Microeng. 18 (3) (2008) 035038.

[17] Zhen-Hua Liu, Lin Lu, Thermal performance of axially microgrooved heat pipe using carbon nanotube suspensions, J. Thermophys. Heat Transf. 23 (1) (2009) $170-175$.

[18] Robert Neal Dean, Daniel Kevin Harris, Ashish Yudhishthir Palkar, Gary Dean Wonacott, Liquid metal-filled micro heat pipes for thermal management of solid-state devices, IEEE Trans. Ind. Electron. 59 (12) (2012) 4888-4894.

[19] Tooraj Yousefi, Mehdi Heidari, Thermal performance enhancement of l-shaped microgrooved heat pipe containing water-based Al2O3 nanofluids, Heat Transf. Eng. 36 (5) (2015) 462-470.

[20] A. Brusly Solomon, A.M. Ram Kumar, K. Ramachandran, B.C. Pillai, C. Senthil Kumar, Mohsen Sharifpur, Josua P Meyer, Characterisation of a grooved heat pipe with an anodised surface, Heat Mass Transf. (2016) 1-11.

[21] Hyun Jin Kim, Seung-Hyun Lee, Soo Bin Kim, Seok Pil Jang, The effect of nanoparticle shape on the thermal resistance of a flat-plate heat pipe using acetone-based $\mathrm{Al}_{2} \mathrm{O}_{3}$ nanofluids, Int. J. Heat Mass Transf. 92 (2016) 572-577.

[22] Stéphane Lips, Frédéric Lefèvre, Jocelyn Bonjour, Nucleate boiling in a flat grooved heat pipe, Int. J. Therm. Sci. 48 (7) (2009) 1273-1278.

[23] Stéphane Lips, Frédéric Lefèvre, Jocelyn Bonjour, Combined effects of the filling ratio and the vapour space thickness on the performance of a flat plate heat pipe, Int. J. Heat Mass Transf. 53 (4) (2010) 694-702.

[24] Jacob Supowit, Thomas Heflinger, Michael Stubblebine, Ivan Catton, Designer fluid performance and inclination angle effects in a flat grooved heat pipe, Appl. Therm. Eng. (2016).

[25] Michael J. Stubblebine, Ivan Catton, Passivation and performance of inorganic aqueous solutions in a grooved aluminum flat heat pipe, J. Heat Transf. 137 (5) (2015) 052901.

[26] Xiaohong Hao, Bei Peng, Yi Chen, Gongnan Xie, Experimental investigation on heat transfer performance of a flat plate heat pipe with mwcnts-acetone nanofluid, J. Heat Transf. 139 (2017) 1294-1304.

[27] Jung-Shun Chen, Jung-Hua Chou, Cooling performance of flat plate heat pipes with different liquid filling ratios, Int. J. Heat Mass Transf. 77 (2014) 874-882.

[28] Gu, Inihal Odabaşi, Modeling of multidimensional heat transfer in a rectangular grooved heat pipe, PhD thesis, Middle East Technical University (METU), 2014

[29] Yiğit Akkuş, Zafer Dursunkaya, A new approach to thin film evaporation modeling, Int. J. Heat Mass Transf. 101 (2016) 742-748.

[30] Yong Li, Zixi Li, Chunyan Chen, Yuying Yan, Zhixin Zeng, Bo Li, Thermal responses of heat pipes with different wick structures under variable centrifugal accelerations, Appl. Therm. Eng. 96 (2016) 352-363.

[31] Lelun Jiang, Jintian Ling, Linzhen Jiang, Yong Tang, Yan Li, Wei Zhou, Jinwu Gao, Thermal performance of a novel porous crack composite wick heat pipe, Energ. Convers. Manage. 81 (2014) 10-18.

[32] Jhan-Hong Liou, Chia-Wei Chang, Chi Chao, Shwin-Chung Wong, Visualization and thermal resistance measurement for the sintered mesh-wick evaporator in operating flat-plate heat pipes, Int. J. Heat Mass Transf. 53 (7) (2010) 14981506.

[33] Hossein Alijani, Barbaros Çetin, Yiğit Akkuş, Zafer Dursunkaya, Experimental thermal performance characterization of flat grooved heat pipes, Heat Transfer Eng. 40 (9-10) (2018) (in press).

[34] Wael I.A. Aly, Moustafa A. Elbalshouny, H.M. Abd El-Hameed, M. Fatouh, Thermal performance evaluation of a helically-micro-grooved heat pipe working with water and aqueous $\mathrm{Al}_{2} \mathrm{O}_{3}$ nanofluid at different inclination angle and filling ratio, Appl. Therm. Eng. 110 (2017) 1294-1304.

[35] Sergii Khairnasov, Alyona Naumova, Heat pipes application in electronics thermal control systems, Front. Heat Pipes (FHP) 6 (1) (2015).

[36] Hao Peng, Juan Li, Xiang Ling, Study on heat transfer performance of an aluminum flat plate heat pipe with fins in vapor chamber, Energy Convers. Manage. 74 (2013) 44-50.

[37] Hyun Jin Kim, Seung-Hyun Lee, Yu Chan Kong, Seok Pil Jang, Joo Ho Choi, Jaye Koo, Long-term reliability of the thermal performance of a flat-plate heat pipe using a prognostics method, Int. J. Heat Mass Transf. 82 (2015) 369-372. 
[38] Jung-Shun Chen, Jung-Hua Chou, The length and bending angle effects on the cooling performance of flat plate heat pipes, Int. J. Heat Mass Transf. 90 (2015) $848-856$.

[39] R.H. Nilson, S.W. Tchikanda, S.K. Griffiths, M.J. Martinez, Steady evaporating flow in rectangular microchannels, Int. J. Heat Mass Transf. 49 (9) (2006) $1603-1618$

[40] Kyu Hyung Do, Sung Jin Kim, Suresh V. Garimella, A mathematical model for analyzing the thermal characteristics of a flat micro heat pipe with a grooved wick, Int. J. Heat Mass Transf. 51 (19) (2008) 4637-4650.

[41] Marin Sigurdson, YuWei Liu, Payam Bozorgi, David Bothman, Noel MacDonald, Carl Meinhart, A large scale titanium thermal ground plane, Int. J. Heat Mass Transf. 62 (2013) 178-183.
[42] Yiğit Akkuș, Hakan I Tarman, Barbaros Çetin, Zafer Dursunkaya, Twodimensional computational modeling of thin film evaporation, Int. J. Therm. Sci. 121 (2017) 237-248.

[43] S.J.S. Morris, Contact angles for evaporating liquids predicted and compared with existing experiments, J. Fluid Mech. 432 (2001) 1-30.

[44] Amir Faghri, Heat pipes: review opportunities and challenges, Front. Heat Pipes (FHP) 5 (1) (2014).

[45] David Reay, Ryan McGlen, Peter Kew, Heat Pipes. Theory, Design and Applications, sixth ed., Butterworth Heinemann, 2014.

[46] Adrian Bejan, Allan D Kraus, Heat Transfer Handbook, vol. 1, John Wiley \& Sons, 2003.

[47] Balram Suman, Modeling, experiment, and fabrication of micro-grooved heat pipes: an update, Appl. Mech. Rev. 60 (3) (2007) 107-119. 